\title{
The Impact of Paternalistic Leadership on Organization Identification: A Moderated Mediation Model
}

\author{
Lin Qiu ${ }^{1}$ \\ ${ }^{1}$ School of Business Administration, South China University of Technology, Guangzhou 510640, China
}

\begin{abstract}
The purpose of this study is to investigate how the two components of paternalistic leadership, namely authoritarianism and benevolence, jointly influence employee organization identification. Using a sample of 182 full-time employees China, this study found that benevolent climate mediated the positive relationship between benevolent leadership and employee organizational identification, and authoritarian leadership moderated the direct effect of benevolent leadership on benevolent climate and the indirect effect of benevolent leadership on organizational identification via benevolent climate. That is, when benevolent leaders simultaneously exhibit authoritarianism, they are more likely to promote perception of benevolent climate among employees who are then more likely to identify with the organization.
\end{abstract}

\section{Introduction}

Organizational identification, defined as the perception of oneness or belongingness with the organization, reflects the underlying bond between the employee and the organization [1]. Employees who strongly identify with their organization feel personally intertwined with the organization and tend to internalize the organization's aims and goals as their own. Although previous research has confirmed that employees identify with their organization when their leaders exhibit transformational leadership, servant leadership, or ethical leadership, very little attention has been paid to the effect of paternalistic leadership, a prevalent leadership style in Chinese business organizations [2]. Given that leadership practices reflect unique cultural idiosyncrasies [3], this study aims to address this gap by examining whether and how paternalistic leadership affects employee organization identification under Chinese cultural background.

This study also probed the possible mediation mechanism between the two aforementioned concepts. Leaders influence not only the behaviors of employees, but the employee perceptions of norms and expectations of appropriate behaviors. Thus, this study adds to the existing literature by examining ethical climate, a type of organizational climate representing the organizational normative systems, policies, and procedures in regards to how ethical issues are resolved [4], as the mediating mechanism.

Paternalistic leadership is typically defined as a leadership style that combines leader authoritarianism and benevolence [5]. These two leadership components are often considered separate, contradictory constructs. Researchers called for research that goes beyond investigating the direct effect of authoritarian and benevolent leadership to examine how these two components jointly affect employees [5]. Therefore, the third purpose of this study was to test the mechanisms underlying this joint effect. By investigating the benevolent ethical climate as a mediator and the authoritarian leadership component as a moderator of the benevolent leadership-organization identification relationship, this study strives to generate knowledge on both how and when benevolent leadership may affect employee organization identification.

\section{Literature Review and Hypotheses}

\subsection{Benevolent Leadership and Organization Identification}

Researchers suggest that effective leaders are particularly adept at fostering employees' identification with the collective [6]. However, little research has been paid to the relationship between paternalistic leadership and organizational identification, despite paternalistic leadership has received growing scholar interest due to the developing economies in China in the past few decades. Family is the fundamental unit of the ethnic Chinese community [7]. In a traditional Chinese family, a father's authority is highly superior to children. Meanwhile, a father has to show love and care to the children. The leaders may analogize the family values and behaviors into the organization by treating subordinates as children [8]. Authoritarian leadership refers to leaders' absolute authority and control over their subordinates, whereas benevolent leadership refers to leaders' holistic concern for subordinates' personal or familial well-being [7].

linqiu@scut.edu.cn 
Employees who strongly identify with their organization feel personally intertwined with the organization and tend to internalize the organization's aims and goals as their own, as consequence are motivated to expend extra effort [9]. According to social exchange theory, employees are likely to increase emotional attachment to the organization while reciprocating the agreeable dealings they receive from their leader. When the leader shows care and concern to individuals, good relationship will be raised. Employees might regard leader's caring behaviors as carrying out responsibilities distributed by the organization and then reciprocate the organization with their psychological attachment to it.

Hypothesis 1. Benevolent leadership is positively related to organization identification.

\subsection{Benevolent Climate as a Mediator}

Ethical climate has been defined as the prevailing perceptions of typical organizational practices and procedures that have ethical content [4]. Victor and Cullen identified three types of ethical climates: egoistic, benevolent, and principled. An ethical climate perceived to be egotistical is related to employees making selfinterested decisions. The general welfare is taken into account more by employees when the ethical climate is perceived as benevolent. Employees make their decisions according to the organizational norms within a principled ethical climate. To avoid an overly complex model, the present study focuses on the benevolent climate.

Organization identification has been believed to represent a psychological linkage between the individual and organization [1]. According to social identity theory, people categorize themselves into groups, whereby they define themselves as part of their social environment [10]. The benevolent climate encourages concern for others, and common interest of all, with an emphasis on mutual assistance and trust among employees [4], which helps to build up affective and cognitive bonds among organization members and hence promotes their organization identification.

Hypothesis 2. Benevolent climate is positively related to organization identification.

Ethical climate is a unique type of organization climate as it is based on values, and the organization's leaders have the primary role in communicating and demonstrating the ethical values to the organization's members [11]. Benevolent leaders provide subordinates with care, protection, and guidance in both work and nonwork domains, which would make subordinates more likely to sacrifice their self-interest for other members in organizations, and to promote a benevolent climate in organizations. A recent empirical study reported a positive relationship between benevolent leadership and benevolent climate [12].

The fundamental rationale of the social exchange theory in explaining employee organizational identification is that employees tend to feel obligated to reciprocate the organization with their psychological attachment to it when the organization has benefited the employees with fulfillment of some psychological needs.
As discussed previously, benevolent leaders may foster a caring ethical climate in an organization, which meets employees' demands for care, protection, and belonging. Thus, this study further argues that the benevolent climate can be an important mediating mechanism in the relationship between benevolent leadership and organizational identification.

Hypothesis 3. Benevolent climate mediates the positive relation between benevolent leadership and organization identification.

\subsection{Authoritarian Leadership as a Moderator}

Paternalistic leadership researchers argue that a single leader has two distinct faces-authoritarianism and benevolence [13], and there might be an interesting interactions between the two components [5]. However, very little empirical research has examined the potential interactions. As an exception, a recent study found that the negative effect of authoritarian leadership was weaker when supervisors exhibited higher levels of leader benevolence [14].

Authoritarian leadership has normally been conceptualized as dysfunctional, due to its consistently negative correlation to desirable employee outcomes [15]. However, the simultaneous enactment of personal care and the establishment of clear authority is presumed to be potentially valued by followers in Chinese context [15]. Researchers have adopted the Yin-Yang philosophy to explain this paradoxical phenomenon, which emphasizes the interdependence and coexistence of two opposing energies [16]. According to the Yin-Yang philosophy, the seemingly opposite and paradoxical components of authoritarianism and benevolence may coexist, and have an interactive and complementary impact on employees [16]. Therefore, authoritarian leadership are likely to augment the positive effect of benevolent leadership on benevolent climate.

Hypothesis 4. Authoritarian leadership moderates the positive effect of benevolent leadership on benevolent climate, such that the relationship is weaker when authoritarian leadership is high rather than low.

Hypothesis 5. Authoritarian leadership moderates the indirect effect of benevolent leadership on employee organization identification via benevolent climate, such that this indirect effect is weaker when authoritarian leadership is high rather than low.

\section{Methods}

\subsection{Participants}

The participants in this study were full-time employees in China. In all, $182(79.1 \%)$ participants completed all sections of the survey. Out of these participants, $53.8 \%$ are female, with the majority (64.8\%) being more than 30 and less than 50. Approximately $83.5 \%$ got college education or more, $74.7 \%$ stayed in the present organization for 4 years or more. 


\subsection{Measurement}

All the measurements were rated on a 5-point scale that ranged from 1 (strongly disagree) to $5=$ (strongly agree).

Benevolent leadership (BeneL) was measured using the 4-item scale developed by Cheng \& Wang [17]. In the present study, Cronbach's $\alpha$ for benevolent leadership was 0.85 .

Authoritarian leadership (AuthL) was measured using the 4-item scale developed by Cheng \& Wang [17]. In the present study, Cronbach's $\alpha$ for authoritarian leadership was 0.85 .

Benevolent climate (BeneC) was measured using the 4-item scale developed by Cullen, Victor, and Bronson (1993) [18]. In the present study, Cronbach's $\alpha$ for benevolent climate was 0.85 .

Organization identification (OID) was measured using a 5-item scale adapted from the scale developed by Mael and Ashforth (1992) [1]. In the present study, Cronbach's $\alpha$ for WFC was .84 .

Control variables. According to previous research, this study statistically controlled for gender, age, organization tenure, position, and education to avoid possible confounding effects.

\section{Results}

\subsection{Descriptive Statistics and Correlational Analyses}

Table 1 shows the means, standard deviations, and intercorrelations of all study variables. The patterns of correlations are consistent with both theory and previous research. Benevolent leadership was positively related to benevolent climate $(r=0.44, p<0.01)$ and OID $(r=0.53$, $\mathrm{p}<0.01)$. Furthermore, benevolent climate was positively related to OID $(r=0.63, p<0.01)$.

TABLE I. DESCRIPTIVE STATISTICS AND CORRELATIONAL ANALYSES

\begin{tabular}{|l|c|c|c|c|}
\hline & AuthL & BeneL & BeneC & OID \\
\hline Gender & 0.10 & -0.13 & $-0.17^{*}$ & $-0.17^{*}$ \\
\hline Age & -0.12 & -0.09 & $0.22^{* *}$ & $0.17^{*}$ \\
\hline Education & 0.11 & -0.01 & $-0.16^{*}$ & $-0.17^{*}$ \\
\hline Tenure & -0.10 & -0.08 & 0.02 & $0.18^{*}$ \\
\hline Position & -0.05 & 0.01 & -0.07 & 0.14 \\
\hline AuthL & 1.00 & & & \\
\hline BeneL & $-0.24^{* *}$ & 1.00 & & \\
\hline BeneC & $-0.19^{*}$ & $0.44^{* *}$ & 1.00 & \\
\hline OID & $-0.29^{* *}$ & $0.51^{* *}$ & $0.63^{* *}$ & 1.00 \\
\hline Mean & 3.37 & 3.07 & 3.53 & 3.78 \\
\hline$S D$ & 0.90 & 0.97 & 0.77 & 0.90 \\
\hline \multicolumn{5}{|c}{$* \mathrm{p}<0.05, * * \mathrm{P}<0.01$}
\end{tabular}

\subsection{Hypothesis Testing}

This study utilized the PROCESS procedure developed by Hayes (2018) to test Hypotheses $1-5$. PROCESS uses an ordinary least squares analytic framework for estimating direct and indirect effects, along with simple slopes and regions of significance for probing interactions and conditional indirect effects in moderated mediation models [19]. This procedure allows for calculating bootstrapped confidence intervals. Table 2 shows the results of the analyses.

This study constructed Model 1 to test Hypothesis 1 and 2, regressing OID onto benevolent leadership, benevolent climate, and the control variables on the basis of 5,000 resamples. The results in Table 2 indicated that OID was positively related to both benevolent leadership $(B=0.26, p<0.001)$ and benevolent climate $(B=0.59, p$ $<0.001$ ), supporting Hypothesis 1 and 2. In addition, the PROCESS results indicated that the $95 \%$ confidence interval of the indirect effect of benevolent leadership on OID through benevolent climate (estimate $=0.21,95 \%$ bias - corrected confidence interval [CI; 0.12, 0.31]) did not contain zero, revealing that the indirect effect was significant. Taken together, Hypotheses 1 - 3 were supported, that is, benevolent climate mediated the positive relationship between benevolent leadership and OID.

To test Hypothesis 4, this study regressed benevolent climate onto benevolent leadership, authoritarian leadership, the product of benevolent and authoritarian leadership, and the control variables on the basis of 5,000 resamples (Model 2). As shown in Table 2, the product term of benevolent leadership and benevolent climate was significant $(\mathrm{B}=0.14, \mathrm{SE}=0.05, \mathrm{p}<0.05)$. To better discern the nature of the significant interaction, we again examined the conditional direct effects of benevolent leadership on benevolent climate at low (1 SD below the mean; Effect $=0.14, \mathrm{SE}=0.08, \mathrm{~ns})$ and high $(1 \mathrm{SD}$ above the mean; Effect $=0.35, \mathrm{SE}=0.08, \mathrm{p}<0.001)$ levels of authoritarian leadership. These results indicate benevolent leadership positively related to benevolent climate when authoritarian leadership is high rather than low, supporting Hypothesis 4.

TABLE II. DESCRIPTIVE STATISTICS AND CORRELATIONAL ANALYSES

\begin{tabular}{|c|c|c|c|c|c|c|}
\hline & \multicolumn{2}{|c|}{ Model 1 } & \multicolumn{2}{c|}{ Model 2 } & \multicolumn{2}{c|}{ Model 3 } \\
\hline & $\boldsymbol{B}$ & $\boldsymbol{S} \boldsymbol{B}$ & $\boldsymbol{B}$ & $\boldsymbol{S} \boldsymbol{B}$ & $\boldsymbol{B} \boldsymbol{B}$ \\
\hline BeneL & $0.26^{* * *}$ & 0.06 & -0.16 & 0.20 & -0.12 & 0.19 \\
\hline AuthL & & & $\begin{array}{c}- \\
0.50^{*}\end{array}$ & 0.18 & -0.44 & 0.18 \\
\hline BeneC & $0.59^{* * *}$ & 0.07 & & & $0.56^{* *}$ & 0.07 \\
\hline $\begin{array}{c}\text { BeneL } \\
* \\
\text { AuthL }\end{array}$ & & & $0.14^{*}$ & 0.05 & $0.10^{*}$ & 0.05 \\
\hline Gender & -0.12 & 0.10 & $-0.22^{*}$ & 0.10 & -0.14 & 0.10 \\
\hline Age & -0.06 & 0.04 & $0.16^{* * *}$ & 0.04 & -0.07 & 0.04 \\
\hline Edu & $-0.13^{*}$ & 0.06 & 0.02 & 0.07 & -0.11 & 0.06 \\
\hline Tenure & $0.12^{* *}$ & 0.04 & -0.09 & 0.05 & $0.11^{*}$ & 0.04 \\
\hline $\begin{array}{c}\text { Positio } \\
\text { n }\end{array}$ & $0.17^{* *}$ & 0.06 & -0.04 & 0.06 & $0.17^{* *}$ & 0.06 \\
\hline$R^{2}$ & \multicolumn{2}{|c|}{0.53} & \multicolumn{2}{c|}{0.33} & \multicolumn{2}{c|}{0.55} \\
\hline
\end{tabular}




\begin{tabular}{|c|c|c|c|}
\hline$F$ & $28.58^{* * *}$ & $10.55^{* * *}$ & $23.78^{* * *}$ \\
\hline
\end{tabular}

To test Hypothesis 5, this study regressed OID onto benevolent leadership, authoritarian leadership, benevolent climate, the product of benevolent leadership and authoritarian leadership, and the control variables on the basis of 5,000 resamples (Model 3). As shown in Table 2, the product term of benevolent leadership and benevolent climate was significant $(\mathrm{B}=0.10, \mathrm{SE}=0.05$, $\mathrm{p}<0.05)$. To better discern the nature of the moderated mediation relationship detailed in Hypothesis 5, this study examined the conditional indirect effects at low (1 SD below the mean; Effect $=0.11, \mathrm{SE}=0.06$, CI $[.01, .24]$ ), mean $($ Effect $=0.19, \mathrm{SE}=0.05, \mathrm{CI}[0.11,0.29])$, and high (1 SD above the mean; Effect $=0.27, \mathrm{SE}=0.06$, CI [0.15, 0.40]) levels of benevolent climate using the bootstrapping procedure. Although all the three conditional indirect effects are significant, the effect sizes are increasing with the increase of authoritarian leadership. Thus, Hypothesis 5 was supported.

\section{Conclusion and Discussion}

In conclusion, this moderated mediation model extends prior research on paternalistic leadership by incorporating the interactive effect of the two components of authoritarianism and benevolence. This model is also one of the first to examine the indirect effect of benevolent leadership on organizational identification through benevolent ethical climate, and the moderating effect of authoritarian leadership on the direct and indirect effects.

This research makes several contributions to the literature. Given seriously scant research on the linkage between paternalistic leadership and employee organization identification, the current study addresses this gap by empirically confirming that benevolent leadership would promote employee organization identification. Along with the findings of many prior research, this study reveals that benevolent leadership helps not only generate benevolent climate, but also foster employee organization identification. In addition, drawing on the social exchange theory, this study finds that benevolent leadership positively affects organizational identification through a benevolent work climate. Since a caring work climate could normally be what employees expect, employees may tend to identify more with their organizations when the benevolent climate forms due to a benevolent leader.

Our research also sheds light on the under-researched but highly important interactive role of leader authoritarianism and benevolence in the formation of a benevolent work climate. To echo the findings of some previous studies, meaning that the simultaneous enactment of personal care and the establishment of clear authority is presumed to be potentially valued by followers in Chinese context, this study confirmed that authoritarian leadership has an interaction effect with benevolent leadership to jointly influence ethical work climate, and subsequently influences employee organizational identification. These findings demonstrate that a full understanding of paternalistic leadership requires an examination of not only the separate effects of its authoritarianism and benevolence components, but also their interaction. Particularly, it is not appropriate to claim that authoritarian leadership is dysfunctional, because results of this study show that a combination of high authoritarian leadership and benevolent leadership fostered benevolent climate and the subsequent organization identification beyond benevolent leadership alone. It seems that the strict demands of authoritarian leaders might remind followers that they have to engage in behaviors in line with the ethical norms and identify with the organization for the sake of the collective good.

\section{Acknowledgment}

This work was supported by the National Social Science Fund of China (18BSH115) and the Thirteenth Five-Year Planning Project of Guangzhou Philosophy and Social Science Fund (2020GZGJ10).

\section{References}

1. F. Mael and B.E.Ashforth, "Alumni and their alma mater: a partial test of the reformulated model of organizational identification", Journal of Organizational Behavior, 1992, vol. 13, pp. 103-123.

2. X. P. Chen, M. B. Eberly, T. J. Chiang, J. L. Farh, and B. S. Cheng. "Affective trust in chinese leaders linking paternalistic leadership to employee performance", Journal of Management, 2014, vol 40, pp. 796-819.

3. L. Ma and Tsui A. S., "Traditional Chinese philosophies and contemporary leadership", The Leadership Quarterly, 2015, vol. 26, pp. 13-24.

4. B. Victor, and J. B. Cullen, "The organizational bases of ethical work climates", Administrative Science Quarterly, 1988, vol. 33, pp. 101-125.

5. E. K. Pellegrini and T. A. Scandura, "Paternalistic leadership: a review and agenda for future research", Journal of Management, 2008, vol. 34, pp. 566-593.

6. B. Shamir, R. J. House, and M. B., "Arthur The motivational effects of charismatic leadership: A selfconcept based theory", Organization Science, 1993, vol. 4, pp. 577-594.

7. J. L. Farh and B. S. Cheng, "A Cultural Analysis of Paternalistic Leadership in Chinese Organizations", in Management and Organizations in the Chinese Context, J. T. Li., A. S. Tsui, and E. Weldon Eds., London: Macmillan, 2000, pp. 84-127.

8. K.S. Yang, Social orientation of the Chinese: Perspective on social interactions, in Chinese psychology and behavior: Conceptions and methods, K. S. Yang and A.B. Yu Eds., Taipei: Laureat, 1993, pp. 87-142.

9. T. Bartram, L. Karimi, P. Stanton, and S. Leggat, "Social Identification: the role of high performance works systems and empowerment", International Journal of Human Resource Management, 2014, vol. 25, pp. 2401-2419. 
10. H. Tajfel, "Social Identity and Intergroup Behaviour", Social Science Information, 1974, vol. 13, pp. 65-93.

11. M. W. Dickson, , D. B. Smith, M. W. Grojean, and M. Ehrhart, "Ethical Climate: The Result of Interactions Between Leadership, Leader Values, and Follower Values", Leadership Quarterly, 2001, vol. 12, pp. 1-21.

12. Y. WU and P. TSAI, "Multidimensional relationships between paternalistic leadership and perceptions of organizational ethical climates", Psychological Reports: Human Resources \& Marketing, 2012, vol. 111, pp. 509-527.

13. S. C. Chan, X. Huang, E. Snape, and C. K. Lam, "The Janus face of paternalistic leaders: Authoritarianism, benevolence, subordinates' organization-based selfesteem, and performance", Journal of Organizational Behavior, 2013, vol. 34, pp. 108-128.

14. A-C. Wang, C-Y.Tsai, S. D. Dionne, and etc., "Benevolence-dominant, authoritarianism-dominant, and classical paternalistic leadership: Testing their relationships with subordinate performance", The Leadership Quarterly, 2018, vol 29, pp. 686-697.
15. A. Bedi, "A meta-analytic review of paternalistic leadership", Applied Psychology: An International Review, 2020, vol. 69, pp. 960-1008.

16. Y. Zhang, D. A.Waldman, Y. L. Han, and X. B. Li, "Paradoxical leader behaviors in people management: Antecedents and consequences", Academy of Management Journal, 2015, vol. 58, pp. 538-566.

17. M-Y Cheng, L. Wang, "The Mediating Effect of Ethical Climate on the Relationship between Paternalistic Leadership and Team Identification: A Team-Level Analysis in the Chinese Context", Journal of Business Ethics, 2015, vol. 129, pp. 639654.

18. J. B. Cullen, , B. Victor, and J. W. Bronson, "The ethical climate questionnaire: An assessment of its development and validity", Psychological Reports, 1993, vol. 73, pp. 667-674.

19. A. F. Hayes, Introduction to Mediation, Moderation, and Conditional Process Analysis. A RegressionBased Approach (2nd ed.). New York, NY: The Guilford Press, 2018. 